\title{
The delivery of evidence-based preventive care for older Americans with arthritis
}

\author{
Jeffrey R Curtis ${ }^{1,2^{*}}$, Tarun Arora ${ }^{2}$, Pongthorn Narongroeknawin ${ }^{1}$, Allison Taylor ${ }^{2}$, Clifton O Bingham $\| l^{3}$, Jack Cush ${ }^{4}$, \\ Kenneth G Saag ${ }^{1,2}$, Monika Safford ${ }^{5}$, Elizabeth Delzell ${ }^{2}$
}

\begin{abstract}
Introduction: Previous research suggests patients with rheumatoid arthritis (RA) may receive suboptimal care with respect to preventive tests and services. We evaluated the proportion of older Americans with RA, psoriatic arthritis (PsA), and osteoarthritis (OA) receiving these services and the specialty of the providers delivering this care.

Methods: Using data from 1999 to 2006 from the Medicare Chronic Conditions Warehouse, we identified persons age $>/=65$ in the national $5 \%$ sample. Over the required five-year observation period, we identified tests and services recommended for older adults and the associated healthcare provider. Services of interest included dual energy $x$-ray absorptiometry (DXA), influenza and pneumococcal vaccination, hyperlipidemia lab testing, mammography and colonoscopy.
\end{abstract}

Results: After accounting for the sampling fraction, we identified 141,140 RA, 6,300 PsA, and 770,520 OA patients eligible for analysis. Over five years, a majority of RA, PsA, and OA patients were tested for hyperlipidemia (84\%, $89 \%$ and $87 \%$ respectively) and received DXA (69\%, 75\%, and 52\%). Only approximately one-third of arthritis patients received pneumococcal vaccination; $19 \%$ to $22 \%$ received influenza vaccination each year. Approximately $20 \%$ to $35 \%$ of arthritis patients never underwent mammography and colonoscopy over five years. Concomitant care from both a rheumatologist and a primary care physician was significantly associated with a greater likelihood of receiving almost all preventive tests and services.

Conclusions: Among older Americans on Medicare, the absolute proportion of persons with arthritis receiving various recommended preventive services and screening tests was substantially less than $100 \%$. Improved comanagement between primary care and arthritis physicians may in part improve the delivery of preventive care for arthritis patients, but novel systematic interventions in this area are needed.

\section{Introduction}

Providing preventive care for complex patients with chronic medical problems is a challenging endeavor [1]. Poor quality of care for many chronic conditions such as osteoporosis has been documented [2,3] despite the availability of evidence-based guidelines and clear recommendations for managing these conditions [4,5]. Recent efforts in the United States to promote high quality care have raised awareness of adhering to evidence-based national recommendations. Modest incentives through the Medicare program provide further motivation to provide certain preventive services [6].

\footnotetext{
* Correspondence: jcurtis@uab.edu

'Division of Clinical Immunology and Rheumatology, Department of Medicine, University of Alabama at Birmingham, 510 20th Street South, FOT
} 805D, Birmingham, AL 35294, USA

(c) 2010 Curtis et al.; licensee BioMed Central Ltd. This is an open access article distributed under the terms of the Creative Commons Attribution License (http://creativecommons.org/licenses/by/2.0), which permits unrestricted use, distribution, and reproduction in any medium, provided the original work is properly cited.

Despite these recent trends that encourage high-quality care, previous research suggests that patients with inflammatory arthritis such as rheumatoid arthritis (RA) receive suboptimal preventive services and care for concomitant comorbidities [7]. Disease and treatmentrelated risk factors for adverse outcomes that are associated with RA and other forms of inflammatory arthritis such as psoriatic arthritis (PsA) make the need for these services even more compelling than for the average person or for individuals with non-inflammatory arthritis such as osteoarthritis (OA). For patients with inflammatory arthritis, biologic medications, non-biologic disease modifying anti-rheumatic drugs (DMARDs), and other treatments that cause immunosuppression (for example, long term glucocorticoid use) are associated with a risk for infection that is increased 
compared to the general population $[8,9]$ and may be partially mitigated with appropriate vaccination. RA is also recognized as an independent risk factor for osteoporosis and fracture [10], making the need for bone mineral density (BMD) testing using dual energy $x$-ray absorptiometry (DXA) more compelling. Persons with RA have an increased risk for certain malignancies such as lymphoma although they have a slightly lower risk for breast and colon cancer [11-14]. Rates of cardiovascular events (for example, acute myocardial infarction) [15-17] are higher in RA and PsA populations, and these patients are recognized to need more aggressive cardiovascular risk factor management than the general population [18].

Despite the clear importance of these preventive services and screening tests, identifying which of a patient's physicians should be responsible for providing these is sometimes unclear. Primary care physicians may be most well-versed and accustomed to providing these services, yet arthritis specialists (for example, rheumatologists) may have more frequent contact with some of these patients. Furthermore, some RA medications may adversely affect risk factors for the conditions of interest (for example, glucocorticoids on BMD, biologic medications on lipid profiles [19-24]), and rheumatologists prescribing these may therefore have greater opportunity to consider how these medications impact their patients' various risk factors. Among many possible factors, a lack of co-management between primary care and arthritis specialists, poor between-provider communication about who should be responsible for providing preventive services and tests, and time pressures on office visits to manage complex patients, may result in patients failing to receive recommended care.

In light of the greater-than-average need to provide most evidence-based preventive services and screening tests to patients with RA and PsA, we used national Medicare data to study the proportion of RA, PsA and OA patients receiving recommended preventive care vis a vis national recommendations for the general population (Table 1). These recommendations advise that all older patients (irrespective of whether or not they have arthritis) receive the services of interest. We compared RA and PsA patients to OA patients, in part used as an internal control group. We selected OA as a comparator condition in order to understand how patients with inflammatory arthritis compared with a similar group of Medicare-enrollees without inflammatory arthritisrelated disease and treatment-associated risk factors for infection, fracture, malignancy, and cardiovascular events. Furthermore, we evaluated the factors associated with receipt of each of the services and tests of interest, including the specialty of the physician providing the service, to understand whether involvement of primary care physicians in the management of comorbidities for arthritis patients was associated with an increased likelihood of patients receiving the recommended preventive tests and services.

\section{Materials and methods \\ Data source and study cohort}

We obtained person-specific, longitudinal administrative claims data from the Center for Medicare and Medicaid (CMS) from 1999 to 2006 for a random 5\% sample of Medicare enrollees. Use of the data was governed by a Data Use Agreement from CMS and approved by the university institutional review board (IRB), which granted a waiver of informed consent. The CMS files used in the analysis included the Denominator, Inpatient, Outpatient, and Carrier files. Physician specialty is identified on each outpatient claim.

In order to identify persons with RA, PsA, and OA, we required at least two ICD9 codes from physician office-visits for these conditions (714.X, 696.0, 715.X) within a 12 -month baseline period using previously described and validated algorithms $[7,25,26]$. In order to assure that all eligible subjects had five years of followup, this baseline year was required to be 1999, 2000 and 2001. This same year was also used to assess other covariates of interest. Following this baseline period, beginning on January 1 of the next calendar year, all individuals were required to have five years of continuous Medicare part A $+B$, and the last date of observation (relevant for the 2001 cohort) was therefore 31 December 2006. Individuals enrolled in a Medicare Advantage plan were excluded (generally $15 \%$ to $20 \%$ of Medicare enrollees) because their administrative data is typically incomplete. Each individual meeting ICD9 diagnosis criteria was assigned to a mutually exclusive category in the hierarchy of PsA, RA, and then OA. The amount of overlap between PsA and RA was low; 0.8\% of RA patients had a concomitant diagnosis of PsA.

\section{Outcomes of interest}

The primary outcomes of interest were receipt of preventive services of various types including dual-energy $\mathrm{x}$-ray absorptiometry (DXA), influenza and pneumococcal vaccination, mammography, colonoscopy, and tests to assess hyperlipidemia (administrative codes available upon request). Patients were considered to have received DXA, pneumococcal vaccination, colonoscopy, and testing for hyperlipidemia if they received this test or service at least once during the five-year observation period. Mammography and influenza vaccination were evaluated at more frequent intervals. Since the focus of this analysis was on preventive testing and not management of abnormal conditions once recognized, patients were credited with having a test no more than once 
Table 1 National recommendations for screening tests and immunizations

\begin{tabular}{|c|c|c|}
\hline Agency & Screening or immunization & Interval for repeat testing \\
\hline$\overline{C D C}$ & Influenza vaccine for adults age 65 and older & one dose every year in the fall or winter \\
\hline CDC & Pneumococcal polysaccharide for adults age 65 and older & $\begin{array}{l}\text { - one dose if unvaccinated } \\
\text { - one-time revaccination at least five years after first dose if given } \\
\text { prior to age } 65\end{array}$ \\
\hline USPTF & Lipid screening for men age 35 and older & Every five years; less or more often if warranted \\
\hline USPTF & $\begin{array}{l}\text { Lipid screening for women age } 45 \text { and older if at increased risk } \\
\text { for heart disease }\end{array}$ & Every five years; less or more often if warranted \\
\hline USPTF & Breast cancer screening for women age 40 and older & Every one to two years \\
\hline USPTF & Colorectal cancer screening for adults age 50 to 75 years old & $\begin{array}{l}\text { - Annual screening with high-sensitivity FOBT } \\
\text { - Sigmoidoscopy every five years, with high-sensitivity FOBT every } \\
\text { three years } \\
\text { - Screening colonoscopy every } 10 \text { years }\end{array}$ \\
\hline USPTF & BMD testing - all women age 65 and older & No specific interval recommended \\
\hline NOF & $\begin{array}{l}\text { BMD testing - women age } 65 \text { and older, and men age } 70 \text { and } \\
\text { older }\end{array}$ & Every two years or more often if warranted \\
\hline
\end{tabular}

CDC, Center for Disease Control; NOF, National Osteoporosis Foundation; USPTF, US Preventive Services Task Force

annually. For each preventive service, coding manuals and literature specific to that service were used by the investigators to identify the relevant ICD-9 and Current Procedural Terminology (CPT) codes for inclusion. Codes were reviewed for appropriateness by a professional medical coder.

\section{Statistical analysis}

Descriptive statistics were used to compare demographics, comorbidities, and health services utilization (for example, number of outpatient physician visits, number of hospitalizations) stratified by type of arthritis. The proportion of individuals with each type of arthritis receiving each service within the five-year follow-up period was shown descriptively. Logistic regression was used to evaluate the relationship between the type of arthritis (RA and PsA referent to OA) and receipt of each of the services of interest. Because mammography and influenza vaccination are recommended more often than once every five years, ordinal regression was used to evaluate mammography $(0,1,>/=2)$ and influenza vaccination (yearly) in categories. The proportionality assumption of the ordinal regression was confirmed qualitatively by using multinomial logistic regression with all categories represented as nominal. The potentially confounding variables that we adjusted for conformed to the Aday-Anderson framework [27], which groups these as predisposing factors (for example, age, gender, race), enabling factors (for example, rural/urban residence, geographic region, median household income defined by census block group, receipt of care from a specialist), and need-based (for example, comorbidities, long term care).

The specialty of the physicians providing each service was also identified. Because the primary focus of this analysis was whether primary care physicians or arthritis specialists provided the services of interest, we evaluated the proportion of patients with at least one service of each type provided by a rheumatologist, a primary care physician, both, or neither. For the analysis of the provider specialty, claims with non-specific physician specialties (for example, a multi-group practice) were excluded and reduced the number of persons eligible for analysis by approximately $3.5 \%$. All analyses were conducted using SAS 9.2 (SAS Institute, Cary, NC, USA).

\section{Results}

Characteristics of the individuals with RA, PsA, and OA are shown in Table 2. As expected, more than twothirds of each of the arthritis cohorts was women, and a majority was white. Approximately one-fourth of RA and PsA patients did not have at least two visits with a primary care physician. In contrast, most care for OA patients was delivered by a primary care physician and not a rheumatologist.

Table 3 shows the proportion of patients with each type of arthritis receiving various services. A majority of women received DXA $(69.2 \%$ with RA, $74.6 \%$ with PsA, and $51.6 \%$ with OA). However, receipt of most other services, irrespective of the type of arthritis, was substantially less than $100 \%$. For example, only about $20 \%$ of arthritis patients received annual influenza vaccination every year for each of the five years of observation. Only one-third of arthritis patients received pneumococcal vaccination at least once. Approximately 20\% to 30\% of women with arthritis did not receive mammography even once, and one-third of arthritis patients did not undergo colonoscopy.

Table 4 shows the prevalence odds ratios for each of the preventive services and tests comparing RA and PsA patients to OA patients. As shown, RA and PsA patients were more likely to receive DXA than OA patients. RA 
Table 2 Descriptive characteristics of older Medicare enrollees with rheumatoid arthritis, psoriatic arthritis, and osteoarthritis

\begin{tabular}{cccc}
\hline Variable & $\begin{array}{c}\text { Rheumatoid } \\
\text { arthritis } \\
\mathrm{N}=141,140\end{array}$ & $\begin{array}{c}\text { Psoriatic } \\
\text { arthritis }\end{array}$ & $\begin{array}{c}\text { Osteoarthritis } \\
\mathrm{N}=6,300\end{array}$ \\
\hline
\end{tabular}

Demographics

Age

65 to 69

70 to 74

75 to 84

$85+$

Gender, \%

Female

Male

Race, \%

Asian

Black

Hispanic

Other

White

Rural/Urban, \%

Urban Core

Not Urban Core

Geographic Region, \%

Northeast

Midwest

West

South

Income in \$, \%

0 to $-<30,000$

30,000 to $<45,000$

45,000 to $<60,000$

60,000 to $<75,000$

$75,000+$

Comorbidities, \%

Myocardial infarction

Heart failure

Cardiovascular disease

Dementia

Chronic pulmonary

disease

Cancer (any)

Hypertension

Osteopenia

Osteoporosis

Closed hip fracture

Physician Specialty ( $\geq 2$

visits), \%

No rheumatology and

no primary care

Rheumatology but no

primary care

Primary care but no rheumatology
Table 2 Descriptive characteristics of older Medicare enrollees with rheumatoid arthritis, psoriatic arthritis, and osteoarthritis (Continued)

\begin{tabular}{|c|c|c|c|}
\hline $\begin{array}{l}\text { Both Rheumatology } \\
\text { and primary care }\end{array}$ & 38.7 & 46.4 & 8.5 \\
\hline Physician Visits, n & $14.3(0,142)$ & $15.2(2,64)$ & $12.8(0,168)$ \\
\hline $\begin{array}{l}\text { Number of days of } \\
\text { inpatient hospitalization, } \mathrm{n}\end{array}$ & $2.2(0,365)$ & $1.7(0,66)$ & $3.0(0,348)$ \\
\hline $\begin{array}{l}\text { Receipt of any Long Term } \\
\text { Care, } \%\end{array}$ & 2.3 & 0.6 & 3.5 \\
\hline \multirow{2}{*}{\multicolumn{4}{|c|}{$\begin{array}{l}\text { Data shown as } \% \text { or as mean (range). All data were assessed in the } 12 \text {-month } \\
\text { baseline period before the start of the five-year observation period. } \\
\text { Totals may not sum to exactly } 100 \% \text { due to rounding. }\end{array}$}} \\
\hline & & & \\
\hline \multicolumn{4}{|c|}{$\begin{array}{l}\text { Cells with a "-"were suppressed due to requirements imposed by data use } \\
\text { agreement restrictions related to small cell sizes }\end{array}$} \\
\hline
\end{tabular}

patients were somewhat more likely to receive pneumococcal vaccination but less likely to undergo cholesterol testing or cancer screening.

Over the five-year observation period, among RA, PsA, and OA patients who had at least one test or service performed, the proportion who had the test or service provided by a rheumatologist (with or without additional tests or services provided by a primary care physician) was $50.2 \%, 43.1 \%$, and $17.5 \%$ for DXA; $17.7 \%$, $14.5 \%$, and $2.3 \%$ for at least one influenza vaccination; $9.6 \%, 6.9 \%$, and $1.1 \%$ for pneumococcal vaccination; and $11.0 \%, 11.4 \%$, and $1.8 \%$ for any hyperlipidemia lab test. Physician specialty was further examined for RA patients in Table 5, which described and controlled for additional factors associated with these services among RA patients (insufficient numbers of PsA patients were available within the data to permit analogous results). As shown, older patients, African Americans, and those with lower incomes were significantly less likely to receive most preventive tests and services. Men were more likely to be tested for hyperlipidemia. Higher income was associated with receipt of all preventive tests and services except for mammography, which varied little across income groups. For DXA, care from a rheumatologist, with or without concomitant care from a primary care physician, was significantly associated with receipt of DXA. In contrast, compared to care provided only by a rheumatologist, RA patients were significantly more likely to receive all other preventive tests and services if they had concomitant care from a primary care physician.

\section{Discussion}

Among older Americans with RA, PsA, and OA our results show that over a five-year observation period, important preventive tests and services such as influenza and pneumococcal vaccination were substantially underutilized. Only $19 \%$ to $33 \%$ of arthritis patients received these vaccinations as recommended. In contrast, 
Table 3 Proportion of patients with rheumatoid, psoriatic, and osteoarthritis receiving preventive services during five years of follow-up

\begin{tabular}{|c|c|c|c|}
\hline & $\begin{array}{c}\text { RA } \\
N= \\
141,140\end{array}$ & $\begin{array}{c}P s A \\
N= \\
6,300\end{array}$ & $\begin{array}{c}\text { OA } \\
N= \\
770,520\end{array}$ \\
\hline DXA, \% (Women) & 69.2 & 74.6 & 51.6 \\
\hline DXA, \% (Men) & 36.7 & 28.6 & 10.2 \\
\hline \multicolumn{4}{|l|}{ Influenza vaccination, \% } \\
\hline Not vaccinated & 17.3 & 15.6 & 18.5 \\
\hline Only 1 vaccination & 8.9 & 10.2 & 10.1 \\
\hline Only 2 vaccinations & 11.6 & 13.0 & 11.9 \\
\hline Only 3 vaccinations & 16.6 & 14.6 & 16.8 \\
\hline Only 4 vaccinations & 24.0 & 27.9 & 22.9 \\
\hline Vaccinated all five years & 21.6 & 18.7 & 19.8 \\
\hline Pneumococcal vaccination, \% & 33.0 & 33.0 & 29.0 \\
\hline \multicolumn{4}{|l|}{$\begin{array}{l}\text { Mammography, \% (women } \\
\text { only) }\end{array}$} \\
\hline None & 29.2 & 20.1 & 28.2 \\
\hline Only 1 & 14.2 & 12.2 & 13.6 \\
\hline 2 or more & 56.6 & 67.7 & 58.2 \\
\hline Colonoscopy, \% & 64.8 & 70.5 & 64.8 \\
\hline Hyperlipidemia lab testing, \% & 83.5 & 88.9 & 87.1 \\
\hline
\end{tabular}

Data shown as \%

Totals may not sum to exactly $100 \%$ due to rounding

screening for other health-related issues with mammography, colonoscopy, DXA and hyperlipidemia lab testing was better, ranging from $40 \%$ to $90 \%$. Except for DXA, rheumatologists provided few of these services; more optimal use of preventive tests and services was associated with concomitant care from both a primary care physician and a rheumatologist. However, about $25 \%$ of patients with inflammatory arthritis did not have concomitant care from a primary care physician.

Compared with the general population, influenza vaccination and breast cancer screening rates reported in our study are lower than those reported by National Committee for Quality Assurance (NCQA) using the Health Plan Employer Date and Information Set (HEDIS) data [2]. HEDIS data are annually obtained from administrative claims, medical record review of a random sample of eligible patients, or a combination of both. The influenza vaccination rate from HEDIS in the general population (69\%) represents the percentage of adults aged 65 and older who receiving an influenza vaccination during the most recent flu season. The breast cancer screening rate (67\%) in HEDIS represents the percentage of women 40 to 69 years who had a mammogram to screen for breast cancer within the last two years. The colonoscopy rates in our cohort are higher than the colorectal cancer screening rate reported in the HEDIS (50\%), despite more liberal definitions used by HEDIS which allow for any of the four
Table 4 Adjusted* association between type of arthritis and receipt of preventive services, referent to osteoarthritis patients

\begin{tabular}{|c|c|c|}
\hline Outcome variable & $\begin{array}{l}\text { Rheumatoid } \\
\text { arthritis } \\
\text { OR }(95 \% \mathrm{CI})\end{array}$ & $\begin{array}{c}\text { Psoriatic } \\
\text { arthritis } \\
\text { OR }(95 \% \mathrm{Cl})\end{array}$ \\
\hline$\overline{D X A}$ & $1.66(1.55,1.77)$ & $1.55(1.19,2.02)$ \\
\hline \multicolumn{3}{|l|}{ Vaccination } \\
\hline Influenza** & $1.02(0.97,1.07)$ & $0.88(0.72,1.07)$ \\
\hline Pneumococcal Vaccine & $1.11(1.05,1.19)$ & $1.04(0.82,1.32)$ \\
\hline Cholesterol lab testing & $0.56(0.52,0.61)$ & $0.79(0.53,1.18)$ \\
\hline \multicolumn{3}{|l|}{ Cancer Screening Tests } \\
\hline $\begin{array}{l}\text { Mammography (Women } \\
\text { Only)** }\end{array}$ & $0.65(0.60,0.69)$ & $0.81(0.59,1.1)$ \\
\hline Colonoscopy & $0.83(0.78,0.88)$ & $0.90(0.7,1.16)$ \\
\hline
\end{tabular}

$\mathrm{Cl}$, confidence interval; OR, odds ratio.

Results in each column are referent to patients with osteoarthritis. Each row represents a unique model.

* adjusted for demographic variables (age, gender, race, geographic region, median household income, rural/urban), predisposing conditions (AMI, CHF, peripheral vascular disease, cardiovascular disease, dementia, COPD, peptic ulcer disease, diabetes with and without complications, paraplegia, chronic kidney disease, cancer, severe liver disease, Alzheimers, hypertension, osteopenia, osteoporosis), prior history of fractures (hip, ankle, clavicle, distal radius/ulna, other radius/ulna, carpal bone, spine, tibia-fibula, humerus, femur, pelvis), health services utilization (hospital days, number of physician visits, days in long term care, physician specialty)

** odds ratios obtained using ordinal logistic regression, grouped as $(0,1,>1=$ 2) for mammography tests, and $(0,1,2,3,4,5)$ for number of annual influenza vaccination

following tests: fecal occult blood test (FOBT) during the measurement year, flexible sigmoidoscopy during the past five years, double contrast barium enema during the five years, and colonoscopy during the past 10 years.

The proportion of arthritis patients with BMD measurement in our study was higher than previously reported for the general U.S. Medicare population age $>/=65$ years; in the general population, only about onethird of women and $<5 \%$ of men had received BMD testing at any time over a seven-year period [28]. Because many rheumatologists have in-office DXAs and bill for this service [28], they likely are more attuned to providing DXA to their patients. We also found that the performance rates were relatively high for hyperlipidemia screening (83\% to $90 \%)$ compared with other preventive services. They were similar to the $81 \%$ to $88 \%$ rates reported by NCQA and others [2]. This may be due to there being fewer barriers to testing and ready accessibility of hyperlipidemia lab testing to physicians of all specialties, in contrast to other services such as DXA and colonoscopy which require access to special equipment or physicians with specialized training in performing this procedure.

Interestingly, starting at approximately age 75 , advancing age was associated with a lower likelihood of receipt of DXA, hyperlipidemia lab testing, and cancer screening, 
Table 5 Factors associated* with preventive tests and services and among RA patients

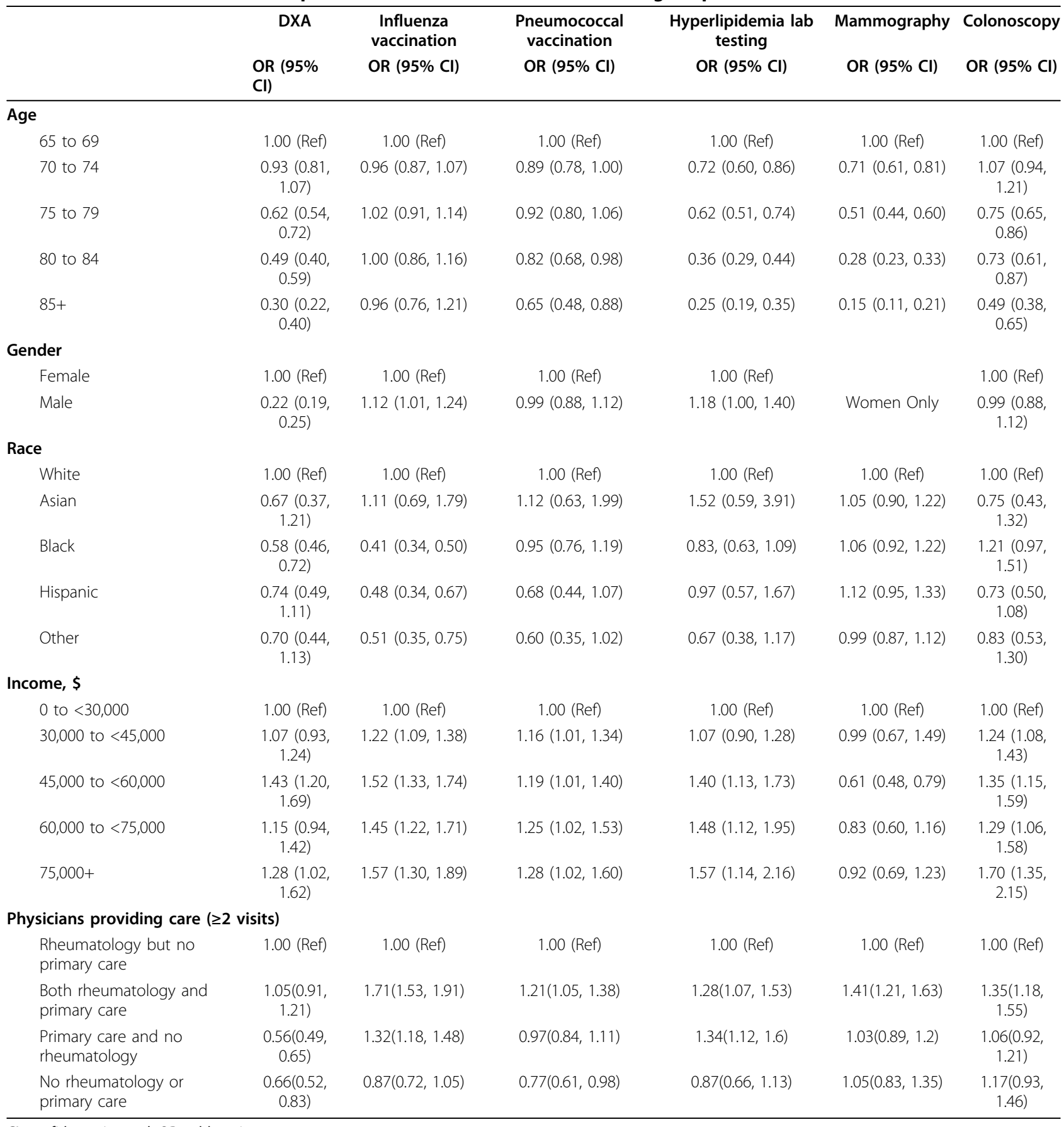

Cl: confidence interval; OR: odds ratio

*adjusted for all factors listed for Table 4.

despite age clearly being a risk factor for fracture, cardiovascular disease (CVD), and malignancy. This may be related to a physician's and patient's lack of expectation of benefit of these services, perhaps in relation to concern for an offsetting mortality risk from other causes. However, because our analysis intentionally included only individuals who remained alive and under observation for five years, our analysis represents a healthier group of individuals with arthritis. For this reason, the preventive tests and services we studied would seem to be even more appropriate than for a less select population where offsetting mortality risk may attenuate the benefit of screening tests. There are likely additional explanations for why older patients were less likely to receive most preventive 
tests and services; these reasons might include more limited access to care (potentially affected by arthritis-related disability), and patients' refusal in light of their own goals and values [29].

Focusing particularly on RA, where more comparative literature is available, our findings are consistent with previous population based studies showing generally low preventive health care and screening services delivered to RA patients. In 2000, MacLean et al. have raised awareness of the need for increased attention to preventive care for patients with RA [7]. This study assessed quality of various services that RA patients received for their arthritis, comorbid diseases, and health care maintenance by using administrative insurance data over a four-year period (1991 to 1995). The overall quality score for health care maintenance, which included colorectal cancer screening (colonoscopy or barium enema once every five years for persons over 50 ), breast cancer screening (mammogram annually for women aged 50 to 70), and cervical cancer screening (Papanicolaou testing every three years for women aged 50 to 70) among eligible RA patients was 42\% [7]. Recently, Aizer et al. reported [30] that over half of patients with RA participating in the Consortium of Rheumatology Researchers of North America (CORRONA) registry had not received BMD testing despite RA being recognized as an independent risk factor for osteoporosis. Using clinical data from a population-based cohort of patients with RA in Rochester with a median follow-up time of 5.4 years, Kremer and colleagues examined the probability of receiving various preventive medical services including influenza vaccination (once a year for persons over 65), pneumococcal vaccination (one time for persons over 65), mammograms (biennially for ages 40 to 49 and annually for those 50 and over), and a lipid profile (once every five years). Complete medical records were reviewed by trained abstractors using a standardized protocol with predefined variables. In this cohort, the proportion of RA patients receiving influenza vaccination, pneumococcal vaccination, mammograms, and lipid screening were $32 \%, 38 \%, 68 \%$, and $88 \%$, respectively [31]. Similar to our results showing that only a small minority of patients receive hyperlipidemia lab testing from rheumatologists, a large not-for-profit health system found that only $2 \%$ of these lab tests were ordered by a rheumatologist [32]. Outside of the U.S., several additional studies have reported $36 \%$ to $81 \%$ influenza and $34 \%$ to $54 \%$ pneumococcal vaccination rates in patients with RA obtained from self-report, patient survey, and/or chart audit, figures which were largely derived from cross-sectional analyses in hospitalbased clinic settings [33-39].

In light of gaps in the use of preventive tests and services we identified for arthritis patients, what can be done to ameliorate this problem? A number of strategies to improve quality of care in rheumatology have been proposed and tested within the boundaries of traditional care processes, with mixed results [40]. Simple interventions involving educating providers via continuing medical education (CME) generally do not change physician behavior or practice [41]. More intensive strategies involving audit and feedback and academic detailing have sometimes been more efficacious [42-45], but effect sizes are often small. Our data suggested better co-management between primary care physicians and rheumatologist might in part improve quality of care. This might be facilitated, for example, by having the arthritis specialists' electronic health record (EHR) notes be generated in real-time and made available (either electronically, or via paper) to the primary care physician, either via electronic exchange (EHR, or facsimile) or hand-carried by the patient [32]. These notes could clearly delineate the patients' health maintenance and preventive services needs and propose the provider responsible for ensuring these services are ordered. At the present, however, electronic health records are used by only a minority of physicians, and EHRs are rarely interoperable. Another potential opportunity may lie in better engaging patients in their own care through use of new personal health records (PHR), which enables patients to better document and perhaps be better advocates for their own healthcare. In light of these emerging information technologies and an increasing focus on quality of care for arthritis patients (at least related to the management of arthritis), new strategies need to be designed and tested to optimize preventive care delivery [46]. It is likely that achieving optimal preventive services in these disease populations will require a shift from fragmented, loosely-defined traditional care to system-based interdisciplinary care of patient populations with better defined provider roles, nurse coordination of care, disease registries, and continuous quality improvement methods [47].

The strengths of our study include evaluation of the entire U.S. Medicare fee-for-service population and thus our results have high generalizability. Unlike many managed care plans with high turnover, patients typically do not disenroll from Medicare, thus allowing us to have a longer period of follow-up (five years, plus a one-year baseline assessment period) than available in most other health plans. Despite these strengths, our results must be interpreted in light of the study design. It is possible that some services such as influenza vaccination were not billed to Medicare and were provided by another agency (for example, a public health department). Patients might also have been offered these services but declined for a variety of reasons in light of their own preferences and values. Another potential reason for a 
patient declining services is the requirement for a copayment, a hypothesis supported by our finding that patients with higher income are more likely to receive these services, with the notable exception of mammography. Additionally, we recognize that the optimal interval for repeating some tests (for example, DXA) is not well-specified, particularly if a previous test was normal. However, except for colonoscopy, where testing is recommended at least every 10 years, our observation period of five years would seem long enough such that at least one test or service of each type should have been provided.

\section{Conclusions}

Based upon recommendations from national guidelines applicable to the general U.S. population, patients with arthritis generally received less than optimal care with respect to receipt of preventive tests and services. Although RA patients were more likely to receive BMD testing, they were significantly less likely to receive evaluation for hyperlipidemia or screening for malignancy compared to OA patients. Based upon higher rates and risk factors for adverse events (for example, serious infections, fracture, malignancy, and CVD among patients with inflammatory arthritis, the need for the preventive tests and services we studied is generally more compelling for RA and PsA patients than for patients with $\mathrm{OA}$ or the general population. Improved co-management between primary care physicians and arthritis specialists is likely to help improve the quality of preventive care for arthritis patients. However, even for patients who had both a rheumatologist and primary care physician, rates of preventive services were less than recommended. New cost-effective, and generalizable interventions to systematically improve the delivery of preventive care are needed, especially for patients with inflammatory arthritis.

\footnotetext{
Abbreviations

BMD: bone mineral density; CME: continuing medical education; CMS: the Center for Medicare and Medicaid; CPT: Current Procedural Terminology; CORRONA: Consortium of Rheumatology Researchers of North America; CVD: cardiovascular disease; DXA: dual energy x-ray absorptiometry; EHR: electronic health record; FOBT: fecal occult blood test; HEDIS: Health Plan Employer Date and Information Set; IRB: university institutional review board; NCQA: National Committee for Quality Assurance; OA: osteoarthritis; PHR: personal health records; PSA: psoriatic arthritis; RA: rheumatoid arthritis

Acknowledgements

This research was supported by a Pharma Foundation Research Grant in Health Outcomes, the Doris Duke Charitable Foundation, the Arthritis Foundation and Amgen, Inc. Only the authors from UAB had access to the Medicare data used. The analysis, presentation and interpretation of the results were solely the responsibility of the authors. Some of the investigators (JRC, KGS) also receive salary support from the National Institutes of Health (AR053351, AR052361) and the Agency for Healthcare Research and Quality (U18 HS016956).
}

\section{Author details}

'Division of Clinical Immunology and Rheumatology, Department of Medicine, University of Alabama at Birmingham, 510 20th Street South, FOT 805D, Birmingham, AL 35294, USA. ²Department of Epidemiology, University of Alabama at Birmingham, 1530 3rd Ave So, Birmingham, AL 35294, USA.

${ }^{3}$ Division of Rheumatology, Department of Medicine, Johns Hopkins University, 5200 Eastern Ave, Baltimore, MD 21224, USA. ${ }^{4}$ Baylor Research Institute, 3434 Live Oak St, Dallas, TX 75204, USA. ${ }^{5}$ Division of Preventive Medicine, Department of Medicine, University of Alabama at Birmingham, 1530 3rd Ave So, Birmingham, AL 35294, USA.

\section{Authors' contributions}

$J C$ and ED participated in all areas of the manuscript preparation. TA contributed to the statistical analysis and review of the manuscript. All others contributed to the design of the study, and the writing and review of the manuscript. All authors read and approved the final manuscript.

\section{Competing interests}

JC received research grants from Merck, Proctor \& Gamble, Eli Lilly, Amgen, and Novartis. JC received consulting/honorarium from Roche/Genentech, UCB, CORRONA, Amgen, Eli Lilly, Merck, and Novartis. ED received research grants from Amgen, and did consulting for Amgen. All other authors declare that they have no competing interests.

Received: 13 April 2010 Revised: 27 May 2010 Accepted: 16 July 2010 Published: 16 July 2010

\section{References}

1. van Weel C, Schellevis FG: Comorbidity and guidelines: conflicting interests. Lancet 2006, 367:550-551.

2. National Committee for Quality Assurance: The State of Health Care Quality 2008. [http://www.ncqa.org/Portals/0/Newsroom/SOHC/SOHC_08. pdf].

3. Curtis JR, Adachi JD, Saag KG: Bridging the osteoporosis quality chasm. J Bone Miner Res 2009, 24:3-7.

4. Quick Reference Information: Medicare Preventive Services. [http://www. cms.hhs.gov/MLNProducts/downloads/mps_guide_web-061305.pdf].

5. National Osteoporosis Foundation: Clinician's Guide to Prevention and Treatment of Osteoporosis. [http://www.nof.org/professionals/ NOF_Clinicians_Guide.pdf].

6. Physician Voluntary Reporting Program. [http://www.cms.hhs.gov/PQRI/ Downloads/PVRPQualityMeasuresList.pdf].

7. MacLean CH, Louie R, Leake B, McCaffrey DF, Paulus HE, Brook RH, Shekelle PG: Quality of care for patients with rheumatoid arthritis. JAMA 2000, 284:984-992.

8. Schneeweiss S, Setoguchi S, Weinblatt ME, Katz J, Avorn J, Sax P, Levin R, Solomon $\mathrm{DH}$ : Anti-tumor necrosis factor alpha therapy and the risk of serious bacterial infections in patients with rheumatoid arthritis. Arthritis Rheum 2007, 56:1754-64.

9. Wolfe F, Caplan L, Michaud K: Treatment for rheumatoid arthritis and the risk of hospitalization for pneumonia: associations with prednisone, disease-modifying antirheumatic drugs, and anti-tumor necrosis factor therapy. Arthritis Rheum 2006, 54:628-634.

10. Kanis JA, Johansson H, Oden A, Johnell O, de Laet C, Melton IL, Tenenhouse A, Reeve J, Silman AJ, Pols HA, Eisman JA, McCloskey EV, Mellstrom D: A meta-analysis of prior corticosteroid use and fracture risk. J Bone Miner Res 2004, 19:893-899.

11. Askling J, Baecklund E, Granath F, Geborek P, Fored M, Backlin C, Bertilsson L, Coster L, Jacobsson LT, Lindblad S, Lysholm J, RantapaaDahlqvist S, Saxne T, van Vollenhoven R, Klareskog L, Feltelius N: Antitumour necrosis factor therapy in rheumatoid arthritis and risk of malignant lymphomas: relative risks and time trends in the Swedish Biologics Register. Ann Rheum Dis 2009, 68:648-653.

12. Askling J, Fored CM, Brandt L, Baecklund E, Bertilsson L, Feltelius N, Coster L, Geborek P, Jacobsson LT, Lindblad S, Lysholm J, RantapaaDahlqvist S, Saxne T, Klareskog L: Risks of solid cancers in patients with rheumatoid arthritis and after treatment with tumour necrosis factor antagonists. Ann Rheum Dis 2005, 64:1421-1426.

13. Baecklund E, lliadou A, Askling J, Ekbom A, Backlin C, Granath F, Catrina Al, Rosenquist R, Feltelius N, Sundstrom C, Klareskog L: Association of chronic 
inflammation, not its treatment, with increased lymphoma risk in rheumatoid arthritis. Arthritis Rheum 2006, 54:692-701.

14. Smitten AL, Simon TA, Hochberg MC, Suissa S: A meta-analysis of the incidence of malignancy in adult patients with rheumatoid arthritis. Arthritis Res Ther 2008, 10:R45.

15. Kremers HM, Crowson CS, Therneau TM, Roger VL, Gabriel SE: High tenyear risk of cardiovascular disease in newly diagnosed rheumatoid arthritis patients: a population-based cohort study. Arthritis Rheum 2008, 58:2268-2274.

16. Nicola PJ, Crowson CS, Maradit-Kremers H, Ballman KV, Roger VL, Jacobsen SJ, Gabriel SE: Contribution of congestive heart failure and ischemic heart disease to excess mortality in rheumatoid arthritis. Arthritis Rheum 2006, 54:60-67.

17. Nicola PJ, Maradit-Kremers H, Roger VL, Jacobsen SJ, Crowson CS, Ballman KV, Gabriel SE: The risk of congestive heart failure in rheumatoid arthritis: a population-based study over $\mathbf{4 6}$ years. Arthritis Rheum 2005, 52:412-420.

18. Peters MJ, Symmons DP, McCarey D, Dijkmans BA, Nicola P, Kvien TK, McInnes IB, Haentzschel H, Gonzalez-Gay MA, Provan S, Semb AG, Sidiropoulos P, Kitas G, Smulders YM, Soubrier MJ, Szekanecz Z, Sattar NG, Nurmohamed MT: EULAR evidence-based recommendations for cardiovascular risk management in patients with rheumatoid arthritis and other forms of inflammatory arthritis. Ann Rheum Dis 2009, 69:325-331.

19. Popa C, Netea MG, Radstake T, Van der Meer JW, Stalenhoef AF, van Riel PL, Barerra P: Influence of anti-tumour necrosis factor therapy on cardiovascular risk factors in patients with active rheumatoid arthritis. Ann Rheum Dis 2005, 64:303-305.

20. Popa C, van den Hoogen FH, Radstake TR, Netea MG, Eijsbouts AE, den Heijer M, van der Meer JW, van Riel PL, Stalenhoef AF, Barrera P: Modulation of lipoprotein plasma concentrations during long-term antiTNF therapy in patients with active rheumatoid arthritis. Ann Rheum Dis 2007, 66:1503-1507.

21. Spanakis E, Sidiropoulos P, Papadakis J, Ganotakis E, Katsikas G, Karvounaris S, Bizaki A, Kritikos H, Boumpas DT: Modest but sustained increase of serum high density lipoprotein cholesterol levels in patients with inflammatory arthritides treated with infliximab. J Rheumatol 2006, 33:2440-2446.

22. Als OS, Gotfredsen A, Christiansen C: The effect of glucocorticoids on bone mass in rheumatoid arthritis patients. Arthritis Rheum 1985, 28:369-375.

23. American College of Rheumatology Ad Hoc Committee on GlucocorticoidInduced Osteoporosis: Recommendations for the prevention and treatment of glucocorticoid-induced osteoporosis. Arthritis Rheum 2001, 44:1496-1503.

24. Eastell R, Devogelaer J, Peel NFA: Prevention of bone loss with risedronate in glucocorticoid-treated rheumatoid arthritis patients. Osteoporosis Int 2000, 11:331-337.

25. Katz JN, Barrett J, Liang MH, Bacon AM, Kaplan H, Kieval Rl, Lindsey SM, Roberts WN, Sheff DM, Spencer RT, Weaver AL, Baron JA: Sensitivity and positive predictive value of Medicare Part B physician claims for rheumatologic diagnoses and procedures. Arthritis Rheum 1997, 40:1594-1600.

26. Singh JA, Holmgren AR, Noorbaloochi S: Accuracy of Veterans Administration databases for a diagnosis of rheumatoid arthritis. Arthritis Rheum 2004, 51:952-957.

27. Aday LA, Andersen R: A framework for the study of access to medical care. Health Sen Res 1974, 9:208-220.

28. Curtis JR, Carbone L, Cheng H, Hayes B, Laster A, Matthews R, Saag KG, Sepanski $R$, Tanner SB, Delzell E: Longitudinal trends in use of bone mass measurement among older americans, 1999-2005. J Bone Miner Res 2008, 23:1061-1067.

29. Harrington JT, Lease J: Osteoporosis disease management for fragility fracture patients: new understandings based on three years' experience with an osteoporosis care service. Arthritis Rheum 2007, 57:1502-1506.

30. Aizer J, Reed G, Onofrei A, Harrison MJ: Predictors of bone density testing in patients with rheumatoid arthritis. Rheumatol Int 2009, 29:897-905.

31. Kremers HM, Bidaut-Russell M, Scott CG, Reinalda MS, Zinsmeister AR, Gabriel SE: Preventive medical services among patients with rheumatoid arthritis. J Rheumatol 2003, 30:1940-1947.
32. Bili A, Schroeder LL, Ledwich LI, Kirchner HL, Newman ED, Wasko MC: Patterns of preventive health services in rheumatoid arthritis patients compared to a primary care patient population. Rheumatol Int 2010.

33. Bridges MJ, Coady D, Kelly CA, Hamilton J, Heycock C: Factors influencing uptake of influenza vaccination in patients with rheumatoid arthritis. Ann Rheum Dis 2003, 62:685.

34. Fahy WA, Farnworth E, Yeldrem KP, Melling GS, Grennan DM: Pneumococcal and influenza vaccination in patients with rheumatic conditions and receiving DMARD therapy. Rheumatology (Oxford) 2006, 45:912-913.

35. Doe S, Pathare S, Kelly CA, Heycock CR, Binding J, Hamilton J: Uptake of influenza vaccination in patients on immunosuppressant agents for rheumatological diseases: a follow-up audit of the influence of secondary care. Rheumatology (Oxford) 2007, 46:715-716.

36. Pradeep J, Watts R, Clunie G: Audit on the uptake of influenza and pneumococcal vaccination in patients with rheumatoid arthritis. Ann Rheum Dis 2007, 66:837-838.

37. Sowden E, Mitchell WS: An audit of influenza and pneumococcal vaccination in rheumatology outpatients. BMC Musculoskelet Disord 2007, 8:58.

38. Lanternier F, Henegar C, Mouthon L, Blanche P, Guillevin L, Launay O: Low influenza-vaccination rate among adults receiving immunosuppressive therapy for systemic inflammatory disease. Ann Rheum Dis 2008, 67:1047.

39. Koutsogeorgopoulou L, Antoniadis C, Vassilopoulos D, Kassimos D: Preventive influenza vaccination for patients with rheumatoid arthritis. A need for an international campaign. Clin Rheumatol 2009, 28:103-104.

40. Teng GG, Curtis JR, Saag KG: Quality health care gaps in osteoporosis: how can patients, providers, and the health system do a better job? Curr Osteoporos Rep 2009, 7:27-34.

41. Davis $D$, Thomson M, Oxman A, Haynes R: Changing physician performance: a systematic review of the effect of continuing medical education strategies. JAMA 1995, 274:700-705

42. Thomson O'Brien M, Oxman A, Davis D, Haynes R, Freemantle N, Harvey E: Educational outreach visits: effects on professional practice and health care outcomes (Cochrane Review). The Cochrane Library Chichester, UK: John Wiley \& Sons, Ltd 2004.

43. Jamtvedt G, Young J, Kristoffersen D, Thomson O'Brien M, Oxman A: Audit and feedback: effects on professional practice and health care outcomes (Cochrane Review). The Cochrane Library Chichester, UK: John Wiley \& Sons, Ltd 2004.

44. Curtis JR, Westfall AO, Allison J, Becker A, Melton ME, Freeman A, Kiefe Cl, MacArthur M, Ockershausen T, Stewart E, Weissman N, Saag KG: Challenges in improving the quality of osteoporosis care for long-term glucocorticoid users: a prospective randomized trial. Arch Intern Med 2007, 167:591-596

45. Colon-Emeric CS, Lyles KW, House P, Levine DA, Schenck AP, Allison J, Gorospe J, Fermazin M, Oliver K, Curtis JR, Weissman N, Xie A, Saag KG: Randomized trial to improve fracture prevention in nursing home residents. Am J Med 2007, 120:886-892.

46. Berwick D: Developing and Testing Changes in Delivery of Care. Ann Intern Med 1998, 128:651-656.

47. Newman ED, Harrington JT: Redesigning the care of rheumatic diseases at the practice and system levels. Part 2: system level process improvement (Redesign 201). Clin Exp Rheumatol 2007, 25:64-68.

\section{doi:10.1186/ar3086}

Cite this article as: Curtis et al:: The delivery of evidence-based preventive care for older Americans with arthritis. Arthritis Research \& Therapy 2010 12:R144. 